\title{
A REGULARIZAÇÃO FUNDIÁRIA NAS FAVELAS NOS CASOS DE "DIREITO DE LAJE": CONSTRUINDO PONTES ENTRE O DIREITO INOFICIAL E O DIREITO VIGENTE.
}

\section{THE LAND REGULARIZATION IN THE SLUMS AND THE "RIGHT OF THE SLAB": BUILDING BRIDGES BETWEEN THE UNOFFICIAL RIGHTS AND THE CURRENT LAW}

\section{RESUMO}

O presente artigo pretende trabalhar de forma analítica a questão da regularização fundiária das favelas, tomando por base teórica a apresentação do conceito de "Direito de Laje". Para a problematização do tema serão utilizados institutos do Direito Civil Brasileiro, tais como o Direito de Superfície e a Usucapião, ressaltando os entraves da aplicação destes aos arranjos comumente observados em regiões favelizadas. Por fim, pretendemos propor uma perspectiva dialógica envolvendo diversos institutos jurídicos como possível solução a questão da regularização das moradias em favelas.

Palavras-chave: Favelas, Informalidade, Regularização fundiária

\begin{abstract}
This article aims to demonstrate analytically the housing issue inside the slums, taking as theoretical basis the new concept about the "right of the slab". To question, traditional institutions of civil law will be used, for example, the right of surface and the adverse possession, highlighting the barriers to their implementation in the slums context. Finally, we intend to propose a dialogical perspective, involving different legal institutions, as a possible solution to the issue of regularization in slum áreas
\end{abstract}

Keywords: Slums, Informality, Land regularization

\footnotetext{
${ }^{1}$ Doutora em Direito pela Universidade Gama Filho - UGF, Rio de Janeiro (Brasil). Professora de Direito pela Universidade Veiga de Almeida - UVA, Rio de Janeiro (Brasil). E-mail: francocorrea@oi.com.br

${ }^{2}$ Mestre em Direito pela Universidade Veiga de Almeida - UVA, Rio de Janeiro (Brasil).

E-mail: julianabarcellos@globo.com
} 


\section{Introdução}

O presente trabalho fundamenta-se sob a ótica do pluralismo jurídico, sustentado por juristas como Boaventura de Sousa Santos que enxergam o direito, sobretudo, como um fenômeno de ordem social, cujas origens advêm tanto da norma posta quanto do costume enquanto prática social. Nesta linha de raciocínio, será discutida a regularização fundiária no âmbito das favelas e apresentada a categoria denominada "Direito de Laje", que se origina justamente de uma interpretação feita com o objetivo de conceder uma roupagem jurídica aos arranjos praticados pelos moradores de favelas, para viabilizar seu acesso à moradia.

Após essa discussão inicial, apresentaremos o direito de moradia, enquanto direito social fundamentado na dignidade humana, o que conduzirá a uma reflexão acerca da existência de uma categoria de cidadania vulnerável, cujo acesso à cidade se da de maneira muito restrita.

Passaremos então a uma breve descrição das praticas imobiliárias observadas no interior das favelas, desde as formas de ocupação do solo até a formação do mercado de locação e venda de imóveis, que se originou e desenvolveu em um contexto de informalidade. As informações utilizadas nesse momento do texto foram extraídas da analise de dados obtidos em anos de pesquisa de campo, realizada sob a coordenação da primeira autora, no seio de uma grande favela carioca.

Feitas essas considerações, iremos avaliar os entraves à aplicabilidade prática dos institutos do direito brasileiro na regularização fundiária das favelas, para então elucidar uma proposta dialógica que envolverá uma serie de institutos jurídicos.

Com relação à metodologia utilizada na pesquisa que originou o presente trabalho, pontuamos que a mesma foi construída através da soma de dados bibliográficos colhidos na melhor doutrina, utilizando, inclusive, o direito comparado, com dados empíricos obtidos, in loco, por meio do método da observação participante.

\section{Favelas brasileiras: Problema ou solução?}

Apesar de firmado na Constituição Federal Brasileira, no artigo $6^{\circ}$, como direito social ${ }^{1}$, o acesso à moradia para a classe pobre ainda se encontra atado à tradição institucionalizada no formato de favelas ${ }^{2}$

\footnotetext{
${ }^{1}$ Art. $6^{\circ}$ - São direitos sociais a educação, a saúde, o trabalho, a moradia, o lazer, a segurança, a previdência social, a proteção à maternidade e à infância, a assistência aos desamparados, na forma desta Constituição.
} 
É fato que as favelas apresentam-se como parte de uma intensa trajetória de desigualdade gerado por um processo de metropolização descuidada. As condições que regularam o processo de produção e circulação da moradia durante décadas no Brasil contribuíram afetivamente que diversas distonias fossem geradas na questão habitacional (RIBEIRO, 1997).

Esse descuido acabou por reforçar as diferenças entre as realidades da cidade, repartindo-a, muitas vezes, entre asfalto e favela, o que intensificou a concepção de opostos, uma oposição estimulada pela antagonização de interesses entre um e outro, haja vista que a favela é atribuída a responsabilidade de decompor o cenário da cidade, fazendo com que haja uma desvalorização dos espaços situados em proximidade de tais conglomerados, além das implicações com a falta de segurança em transitar nessas localidades.

Por outro lado, a favela se consubstancia como uma solução viável para mais de 11 (onze) milhões de pessoas no Brasil ${ }^{3}$. Segundo dados do IBGE em seu último CENSO (2010), foram identificados 6.329 aglomerados subnormais, em 323 municípios do País. Trata-se de um fenômeno majoritariamente metropolitano, pois 88,2\% dos domicílios em favelas estavam concentrados em regiões com mais de 1 (um) milhão de habitantes. As regiões metropolitanas de São Paulo, Rio de Janeiro e Belém, somadas, concentravam quase a metade (43,7\%) do total de domicílios em assentamentos irregulares do País ${ }^{4}$. O somatório demonstra uma realidade cruel, pois são , mil es de domic lios m dia de , a itantes domic lio), em estado de aglomerados subnormais 5 .

Portanto, como se observa, morar em favela representa uma solução de vida para milhões de brasileiros que experimentam cidadanias vulneráveis, muito longe do alcance de modelos de cidadanias plenas. Entretanto, mesmo que o modo de vida e de reprodução social que vivenciam seja a solução possível para suas sobrevivências, usualmente os favelados são

\footnotetext{
${ }^{2}$ Entende-se por favela a área predominantemente habitacional, caracterizada por ocupação clandestina e de baixa renda, precariedade da infraestrutura urbana e de serviços públicos, vias estreitas e alinhamento irregular, ausência de parcelamento formal e vínculos de propriedade e construções não licenciadas, em desacordo com os padrões legais vigentes.

${ }^{3}$ Censo do IBGE de 2010

${ }_{5}^{4}$ Resultado obtido pelo IBGE no Censo 2010 sobre Aglomerados subnormais.

${ }^{5}$ O Manual de Delimitação dos Setores do Censo 2010 classifica como aglomerado subnormal cada conjunto constituído de, no mínimo, 51 unidades habitacionais carentes, em sua maioria, de serviços públicos essenciais, ocupando ou tendo ocupado, até período recente, terreno de propriedade alheia (pública ou particular) e estando dispostas, em geral, de forma desordenada e densa. A identificação atende aos seguintes critérios:

a) Ocupação ilegal da terra, ou seja, construção em terrenos de propriedade alheia (pública ou particular) no momento atual ou em período recente (obtenção do título de propriedade do terreno há dez anos ou menos); e b) Possuírem urbanização fora dos padrões vigentes (refletido por vias de circulação estreitas e de alinhamento irregular, lotes de tamanhos e formas desiguais e construções não regularizadas por órgãos públicos) ou precariedade na oferta de serviços públicos essenciais (abastecimento de água, esgotamento sanitário, coleta de lixo e fornecimento de energia elétrica).
} 
vistos como um dos grandes problemas para as cidades em que habitam. Tal visão, entretanto, além de explicitar um dilema já institucionalizado na atualidade, não inspira soluções melhores de acesso à moradia, do que as já encontradas pelos moradores de favelas (CORRÊA: 2012).

Essas contradições não são novas e, ao analisar a trajetória da ocupação irregular em grandes centros urbanos, em especial como ocorreu na cidade do Rio de Janeiro, berço histórico das favelas, nota-se que os descuidos dos agentes públicos, no que tange à uma cidadania igualitária, viabilizada através execução de políticas públicas efetivas, acabaram por fomentar tais dilemas, que datam de mais de um século.

O dissenso na visão das favelas no Rio de Janeiro não é novidade. Uma breve analise da trajetória da ocupação irregular, de longa data, assinala o descaso dos agentes públicos quanto ao acesso à moradia de segmentos sociais fragilizados, com baixo poder aquisitivo. Desde os "mocam os" a itados por escravos at depois da a olição da escravatura persiste o problema da moradia de segmentos da população que vive em situação de vulnerabilidade. Mesmo quando da implantação dos primeiros projetos de urbanização da cidade do Rio de Janeiro, o abrigo de segmentos sociais menos favorecidos foi descartado, como ocorreu com os cortiços. Tal exclusão, entretanto, não veio sozinha e muito contribuiu para inviabilizar a formação de uma cidadania igualitária e inclusiva, que permitisse o acesso a direitos, tais como, estar apto a celebrar um contrato de trabalho, receber amparo à preservação da saúde, e ter acesso à educação, embora a Constituição vigente os mantenha como direitos sociais formalmente instituídos em nosso país, igualmente, para todos os brasileiros.

As causas da existência das favelas brasileiras podem ser muitas, mas, sem dúvida, a ausência histórica de políticas públicas destinadas a promover o acesso à moradia para faixas menos favorecidas da população, não poderia ser afastada. Tanto durante a escravidão, como após a a olição dos escravos, sugiram os rasileiros "sem teto". Desde então, somente aumentaram as ocupações irregulares que acolhem suas casas. No entanto, as políticas que lhes são endereçadas, quase sempre encerram punições como remoções para outros locais, quase sempre longínquos, afastados de seus pontos de trabalho e de suas relações pessoais. Outras vezes, a população favelada é obrigada a desocupar o bairro em que vivia, sem indicação de outros locais para viver e, junto com a decisão estatal vão também seus pertences, certamente, adquiridos com sacrifício.

Essas distorções iniciais se estratificaram assumindo novos contornos, nunca tratados concretamente como uma realidade da cidade, sendo apenas tomados como um problema passível de mitigação, com atitudes políticas estanques. Tais atitudes demonstraram e ainda 
demonstram o não reconhecimento de uma cidadania urbana, reflexo de um contexto de cidadania universal, que afasta o sentido único da moradia como mera mercadoria, acolhendoa, antes de tudo, como um direito respaldado na dignidade humana.

Portanto, a questão habitacional no Brasil da atualidade ainda tem conduzido milhões de brasileiros uma vida precária, excluída do direito basilar à moradia digna e à posse de um endereço residencial, reconhecido oficialmente na sociedade. Tal imbróglio resulta em uma cadeia de exclusões. Moradores de favelas, não detêm endereços residenciais oficiais. Logo, tem dificuldade de encontrar trabalho no mercado formal, de abrir conta bancária, de ter acesso a crédito, de receber correspondência, de ter acesso à Justiça, de aquisição de propriedade legal, dentre outros direitos que o Estado, por determinação constitucional, lhes deveria assegurar.

Neste aspecto, destaca Cláudia Franco Corrêa:

A lacunosa atuação estatal contribui sobremaneira para as reações sociais que visam, sobretudo, à autoinclusão no espaço da cidade. Dessa maneira, pode-se afirmar que as favelas são, antes de tudo, um esforço de resistência, posto que raros foram os momentos em que o ente público pensou na população pobre quando da distribuição dos recursos e bens urbanos (CORRÊA: 2012).

A real necessidade de inclusão no espaço da cidade forçou considerável inventividade dos moradores de favelas, haja vista que, sem opção de inserir-se na estrutura da moradia legal, pois a aquisição do direito de propriedade lhes é inacessível, os moradores de favelas constroem arranjos sociais que lhes possibilitam participar de uma estrutura de circulação de riquezas que embora inoficial, articula suas vidas cotidianas, diante da ausência do Estado (CORRÊA: 2012).

Assim, percebemos, dentro das favelas, a construção de um mercado imobiliário próprio e de maneiras diferenciadas de acesso a serviços públicos com destaque a presença de um mercado imo iliário local que está al m da superf cie. Nele so ressai um "direito de laje", que não apenas contribui para verticalizar as moradias como concede considerável impulso as transações imobiliárias sem, contudo, assegurar a titularidade das propriedades, o que comumente oferece situações de insegurança e de conflito, uma vez que tais moradias não são reconhecidas pelo direito oficial brasileiro. 


\section{2. "Direito de Laje" e a criatividade dos favelados: $O$ direito que está na vida, mas não na Lei.}

Pontua-se, preliminarmente, as circunstancias socioantropologicas já contextualizadas que levaram os moradores de favelas a adotar uma maneira tão sui generis de moradia, sob a forma de crescimento vertical, como meio de alcançar e concretizar um direito tão fundamental.

O "Direito de Laje", por conseguinte, consiste em uma prática resultante da necessidade de institucionalizar arranjos que empreendam segurança para as formas de morar, oriundas da autoconstrução. Foram as próprias práticas que consolidaram regras socializadas na favela que ditaram as maneiras de como construir e como negociar.

Por definição podemos afirmar que o "Direito de Laje" é uma categoria imobiliária comum em favelas, de maneira especial nas favelas cariocas, que traduz a apropriação de um bem imóvel em posição verticalizada, também sem previsão no ordenamento jurídico pátrio, pois decorre da plena ocupação horizontal de moradias primitivas, constituídas sobre o solo, na superfície terrestre.

Segundo Corrêa, o "Direito de Laje" ocorre de diversas formas, contudo, a mais recorrente é quando um morador de uma habitação térrea vende a outra pessoa o "direito" de construir moradia sobre a laje de sua casa. Outra forma em que se manifesta o "Direito de Laje" quando o futuro morador do terreno de superf cie vende a sua laje sem que sua casa esteja pronta ou sem, sequer, que a laje esteja construída. Nesses casos o vendedor usa o dinheiro da venda da laje para construir ou para dar acabamento à sua futura moradia. Compradores e vendedores admitem tacitamente o "Direito de Laje", mesmo em circunstâncias especiais, como o caso do "contrato" de venda de laje não construída. (CORRÊA: 2012)

O "Direito de Laje" concede nova versão à arquitetura da favela, configurando moradias verticais, como pequenos edifícios, pois o morador que construiu sua casa sobre uma laje pode vender a laje de cobertura de sua casa a outro comprador, o que caracteriza mais uma modalidade de transação envolvendo o "Direito de Laje" do comprador, que assim tem acesso a sua moradia. Outra modalidade em que se faz presente o "Direito de Laje" ocorre quando o comprador de uma casa construída na superfície compromete-se a construir um prédio com alguns andares, geralmente de 3 (três) ou 4 (quatro), cujos espaços 
são dispostos em quitinetes, ${ }^{6}$ destinadas à locação de unidades superpostas para moradia de terceiros, exceto uma delas, que é destinada à moradia do vendedor da casa primitiva.

É fato que o processo de verticalização das favelas em grandes centros urbanos, como o Rio de Janeiro, cresce consideravelmente a partir da década de oitenta.

No caso do Rio de Janeiro, o governo Brizola representou o momento da consolidação dos investimentos feitos pelos próprios moradores de favela em suas casas, representando a passagem do barracão de madeira e zinco à casa de alvenaria, como esclarece Lessa, ao considerar os efeitos da política do Governador Leonel Brizola, de maneira especial, no processo de verticalização das favelas cariocas, tendo em vista que a alvenaria permitiu a construção de casas de dois e três andares, que se multiplicaram com velocidade. (LESSA: 2005). Tais nuanças permitem constatar que o crescimento das favelas brasileiras na atualidade se consolida muito mais verticalmente do que horizontalmente.

Neste aspecto, a verticalização de moradias atrav s do "Direito de Laje" se apresenta também como fonte de rendimentos de aluguel para quem empreende a obra, seja o comprador da casa primitiva ou seu próprio dono. Desse modo, as várias modalidades em que o "Direito de Laje" se manifesta contri uem para a vitalidade do mercado imo iliário local, cujas transações "contratuais" de compra e venda ou de locação ficam legitimadas na favela, pois atendem à demanda por moradia e, de certo modo, permitem a realização do direito de acesso à moradia, embora tais soluções, como já dito, permaneçam à margem do enquadramento legal posto.

Neste quesito, esclarece Marco Aurélio Bezerra de Melo, que a situação dos moradores de favelas quanto à segurança jurídica de suas aquisições habitacionais se encontra fragilizada, vez que enquanto a situação do dominus soli não for regularizada a relação estabelecida entre moradores adquirentes será meramente obrigacional e a segurança jurídica dessas transações estará na boa-fé das pessoas que contratam ou nas mãos da Associação de Moradores, local que comumente costuma intervir em tais negociações, atuando de modo semelhante aos cartórios de registros imobiliários (MELO: 2015).

A questão que afeta de modo especial à problemática do presente trabalho, situa-se justamente na falta de respaldo jur dico para o "Direito de Laje" e consequentemente, na

\footnotetext{
${ }^{6}$ Quitinete é um apartamento de pequena dimensão formada geralmente por apenas um quarto, um banheiro e uma sala/cozinha, sendo todos com um espaço extremamente pequeno.
} 
dificuldade de executar a regularização fundiária em tais situações, até porque, comumente as construções erigidas como favelas estão localizadas em terrenos públicos e, portanto, com óbices legais na aplicabilidade do instituto da usucapião, como regra ${ }^{7}$.

Nesta perspectiva podemos dizer que o "Direito de Laje" uma realidade social, mas uma invisibilidade jurídica.

Portanto, a falta de parâmetros claros que permitam estabelecer um relacionamento social que seja resultado da conexão entre o real e o legal, favorece a institucionalização de fato de práticas sociais reiteradas em conglomerados habitacionais favelizados. O resultado não é dos melhores, pois a ausência de parâmetros permite a consolidação de uma segregação socioespacial, tendo em vista que fora do sistema oficial, desenvolve-se dentro desse espaço outro direito, que passa a ter vigência paralelamente ao direito oficial brasileiro (CARBONARI: 2008).

O próprio Estatuto da Cidade impõe como dever do Estado a necessidade imperiosa de regularização fundiária, através de instrumentos jurídicos, que não apenas assegurem a implementação do acesso ao direito de morar como categoria de moradia, mas, sobretudo, impõe a necessidade de que os moradores de favelas possam desfrutar do direito de propriedade com todas as suas faculdades inerentes, haja vista que, a manutenção do não reconhecimento oficial das moradias em favelas, ou, a manutenção de sua ilegalidade acaba por demonstrar exclusões socioeconômicas e jurídicas e não contribui para a inclusão da população moradora de favelas em um nível de cidadania condizente com o estágio avançado que a civilização humana alcançou na atualidade. Do mesmo modo, não contribui para que os brasileiros desfrutem de uma cidadania urbana igualitária (CORRÊA: 2012).

\section{Construindo pontes entre o "Direito de Laje" e a regularização fundiária.}

Como já salientado, o "Direito de Laje" não encontra respaldo jur dico no direito brasileiro, ou seja, o referido instituto além de informal é atípico. A tarefa, portanto, que assumimos no presente trabalho é questionar a aplicação específica de um tipo normativo, sem que sejam analisadas as nuanças sui generis dos casos que envolvam o "Direito de Laje", de modo que, através de uma construção dialógica, seja viável a regularização das moradias erigidas na modalidade do "Direito de Laje", objetivo precípuo do nosso paper.

\footnotetext{
${ }^{7}$ A usucapião de terrenos pertencentes ao poder público encontra expressa proibição no Art. $183 \S 3^{\circ}$ da CRFB/1988, tal proibição também pode ser encontrada no art. 102 do CC/02.
} 
Cremos que a adaptação a fórceps de qualquer instituto jurídico posto nas situações em que se apresentam as habitações em favelas, corre sério risco de não resistir no plano da efetividade. Desta maneira, somos favoráveis a tese de que a solução do problema apresentado situa-se na interação dialogal de institutos jurídicos, ou seja, propomos uma interrelação de fontes, uma atividade dialógica consistente que possa, como resultado, promover a efetiva regularização fundiária e, consequentemente, o acesso ao direito de moradia digna e regular a milhões de brasileiros.

Adverte-se que a definição de regularização fundiária absorvida e contextualizada em nossa problemática é aquela encontrada no teor da Lei 11.977 de 07 de julho de 2009, que dispõe sobre o Programa Minha Casa, Minha Vida - PMCMV e a regularização fundiária de assentamentos localizados em áreas urbanas, que concebe em seu artigo 46 o que segue:

Art. 46. A regularização fundiária consiste no conjunto de medidas jurídicas, urbanísticas, ambientais e sociais que visam à regularização de assentamentos irregulares e à titulação de seus ocupantes, de modo a garantir o direito social à moradia, o pleno desenvolvimento das funções sociais da propriedade urbana e o direito ao meio ambiente ecologicamente equilibrado.

Assim, pontuamos, neste momento, referencial teórico adequado para fundamentação da resposta a problemática que desejamos enfrentar.

Alguns juristas defendem a possibilidade de aplicação do Direito de Superfície ao "Direito de Laje", por ser aquele um direito real so re coisa al eia, podendo ser visto como um desdobramento do Direito de Propriedade, segundo o disposto no artigo 1.369 do Código Civil Brasileiro $^{8}$ e na Lei ${ }^{\circ} 10.257 / 01$ (Estatuto da Cidade), artigos 21 a $24^{9}$, descrito da seguinte maneira (LIRA: 1997):

É o direito real autônomo, temporário ou perpétuo, de fazer e manter construção ou plantação sobre ou sob terreno alheio; é a propriedade - separada do solo - dessa construção ou plantação, bem como é a propriedade decorrente da aquisição feita ao dono do solo de construção ou plantação nele já existente.

O Direito de Superfície caracteriza-se pelo afastamento do princípio jurídico que prega que "tudo o que se edifica ou planta, adere ao solo" omne quod solo inaedificatur, vel implantur solo cedit), noção basilar do instituto do Direito Civil, conhecido como

\footnotetext{
${ }^{8}$ Código Civil - Artigo 1.369. O proprietário pode conceder a outrem o direito de construir ou de plantar em seu terreno, por tempo determinado. Mediante escritura pública devidamente registrada no cartório de registro de imóveis.

${ }^{9}$ Lei 10.257/2001 - Art. 21. O proprietário urbano poderá conceder a outrem o direito de superfície do seu terreno, por tempo determinado ou indeterminado, mediante escritura pública registrada no cartório de registro de imóveis.
} 
acessão $^{10}$. Por meio desse desdobramento do solo, através do qual se destaca deste a superfície, acredita-se que seja viável que cada um possua um valor de mercado diferenciado e reduzido, tornando mais acessível o Direito de Moradia. O interessado poderia adquirir somente a construção ou a superfície do solo, para nela edificar, sem ter que adquirir o solo, que continuaria pertencendo a outrem. Seria, de acordo com os especialistas do assunto, um vértice da funcionalização do direito de propriedade, apresentando um contexto mais amplo de redefinição da propriedade, conjugando em sentido plural o domínio, visando à função social desse mesmo direito como instrumento da justiça social (LIRA: 1997).

Mas uma indagação surge ao analisar o referido instituto: Como aplicar o Direito de Superf cie ao "Direito de Laje" se aquele pressup e necessariamente a propriedade formal como fato gerador?

A possível aplicação passa a ser questionada, posto que o respectivo direito real só pode ser abrigado, segundo o sistema legal brasileiro, quando há o direito de propriedade

á um desdo ramento da propriedade), o que não ocorre nos casos que envolvem "lajes", haja vista que, na maioria das vezes, ou a construção sobre a laje foi edificada em terreno particular invadido e é objeto de posse, ou foi construída amparada em ato de concessão ou de autorização de uso celebrada pelo poder público.

Outro dado relevante a ser suscitado baseia-se no fato de que as ocupações de áreas públicas situam-se como detenção, não configurando uma posse segura para habilitar o Direito de Superfície, como regra. Nos dois últimos casos, a edificação estaria construída sobre terras que seriam patrimônio público, o que inviabilizaria a aspirada aplicação, sob pena de haver o desdobramento da propriedade pública e privada no mesmo espaço, possibilidade esta, que o ordenamento jurídico brasileiro atual também não prevê (CORREA: 2012).

Alguns juristas descortinam a possi ilidade de aplicar ao "Direito de Laje" o Direito de Sobrelevação ${ }^{11}$, uma espécie do direito de superfície que algumas legislações estrangeiras desenvolveram, como é o caso da Suíça, Itália e Portugal. É a posição do eminente professor Ricardo Lira.

Outro aspecto interessante a abordar quanto às formas de utilização da superfície é o direito de sobrelevação ou superfície em segundo grau. O superficiário concede a um segundo concessionário o direito de construir

\footnotetext{
${ }^{10}$ Acessão “ a união f sica entre duas coisas, de mat rias indissolúveis, um conjunto em que uma das partes, embora possa ser reconhecível, não guarda autonomia, sendo subordinada, dependente do todo".

${ }^{11}$ Nesse sentido: Lira, Rosenvald e Farias.
} 
sobre a sua propriedade superficiária. Essa forma de utilização da superfície é contemplada no Código suíço. De resto, a criatividade do brasileiro também a utiliza no direito informal, nas formações favelares, onde o titular da moradia cede a outrem o direito de laje.

Segundo Lira, a sobrelevação é a possibilidade de o titular da propriedade superficiária construir ou conceder a um terceiro que construa sobre a superfície da qual detém a propriedade. Tal instituto prevê o direito de construir sobre edifício alheio, apresentando hibridismo entre a superfície e a propriedade horizontal (LIRA: 2002). A constituição dessa modalidade de direito está condicionada às regras da superfície e às limitações da propriedade horizontal. Uma vez edificando sobre o prédio situado na superfície, a situação desemboca por completo na propriedade horizontal. Assim, a sobrelevação cria a possibilidade de o construtor vender o prédio, com reserva do espaço aéreo, pela intenção de construir $a$ posteriori (ASCENSÃO: 2000). O que também não seria aplicável ao caso das “lajes”, pelas mesmas raz es já explicitadas, dada a inexistência do direito de propriedade formal.

Como é possível considerar, há um entrave legal para que seja feita a adequação do direito de sobrelevação, na medida em que se apresenta, nas situações gerais em que o "Direito de Laje" se configura nas favelas, no geral.

Dentro desse mesmo contexto também devemos salientar a relevância da cisão, posto sua importância no enfretamento de nossa problemática.

Marcos Aurélio Bezerra de Melo adverte que a superfície pode recair sobre imóvel com acessões já implantadas, consolidando o instituto da cisão entre proprietário do solo e a propriedade superficiária. Pontua ainda o autor que, a despeito do silencio lamentável da lei civil quanto a tal possibilidade, o referido instituto, expressamente admitido no direito civil português $^{12}$, deve ser considerado como viável em nosso ordenamento jurídico (MELO: 2015).

Neste sentido, o Enunciado número 250 da III Jornada de Direito Civil do Conselho da Justiça Federal /STJ conclui pela admissão do direito de superfície por cisão.

Ricardo Pereira Lira apresenta as diversas maneiras de constituição da superfície por cisão. A primeira ocorre quando o dominus soli concede a outrem a superfície de área já plantada ou construída; na segunda, o dominus soli outorga a propriedade reservando para si a plantação ou construção; e a terceira, o dominus soli destina a propriedade do solo para uma pessoa e a superfície para outra (LIRA: 1997).

\footnotetext{
${ }^{12}$ Art. 1528. O direito de superfície pode ser constituído por contrato, testamento ou usucapião, e pode resultar da alienação de obra ou árvores já existentes, separadamente da propriedade do solo.
} 
Mas como aplicar o Direito de Superfície com seus desdobramentos - sobrelevação e cisão - ao caso do "Direito de Laje" viabilizando, portanto, a regularização fundiária?

Cremos que a inicialmente há de ser necessária a regularização originária do solo para, a partir desse primeiro passo, conjugarmos outras aplicações de institutos regularizadores.

No teor da Lei 11.977/2009, reencontramos o instituto da legitimação da posse como via procedimental executória para se alcançar a regularização fundiária, diga-se reencontramos, pois a legitimação de posse foi instituída, no direito brasileiro, pela lei imperial 601, de 1850.

Na lei 11.977/2009 há tratamento normativo para o referido instituto, alocando-o como um dos efeitos da regularização fundiária.

Art. 47. Para efeitos da regularização fundiária de assentamentos urbanos, consideram-se:

(...)

IV - legitimação de posse: ato do poder público destinado a conferir título de reconhecimento de posse de imóvel objeto de demarcação urbanística, com a identificação do ocupante e do tempo e natureza da posse;

O ato do poder público a que se refere o citado artigo 47 enseja procedimento administrativo e cartorial. Havendo a autorização do ente municipal será procedido um auto de demarcação urbanística que deve ser instruído com plantas e certidões imobiliárias. Após a feitura do auto de demarcação, este deverá ser encaminhado ao Registro de Imóveis para que o oficial do cartório proceda à busca para identificar o proprietário da área a ser regularizada. Uma vez identificado, o proprietário será notificado (por correio ou pessoalmente), bem como os confrontantes da área demarcada, para, querendo, apresentarem impugnação à averbação de demarcação urbanística no prazo de 15 dias. Não sendo localizados os interessados, deverá proceder a notificação por meio de edital.

O que se nota a partir desse momento é a abertura de uma série de possibilidades impugnatórias, e que o oficial do cartório funcionará com mister judicializante, pois ficam sob sua responsabilidade vários procedimentos, inclusive conciliatórios, como adverte o $\S 9^{\circ}$ do artigo 7: “O oficial de registro de imóveis deverá promover tentativa de acordo entre o impugnante e o poder pú lico".

Após tais tramites, ocorrerá a averbação do auto de demarcação onde o poder público deverá elaborar um projeto de parcelamento que também será registrado em cartório imobiliário, concedendo título de legitimação de posse aos ocupantes cadastrados. 
Dessa maneira, a legitimação de posse devidamente registrada constituirá direito em favor do detentor da posse direta para fins de moradia (artigo 59), desde que não sejam concessionários, foreiros ou proprietários de outro imóvel urbano ou rural e que não sejam beneficiários de legitimação concedida anteriormente. Os lotes, objeto de legitimação, não podem ultrapassar a metragem de $250 \mathrm{~m}^{2}$.

Todavia, ainda não terá o possuidor o direito de propriedade, que só se consubstanciará após decorrerem cinco anos do registro de legitimação. Nesse caso, haverá a conversão da legitimação da posse em propriedade pela usucapião, segundo determina o artigo 60 da lei em comento:

Sem prejuízo dos direitos decorrentes da posse exercida anteriormente, o detentor do título de legitimação de posse, após 5 (cinco) anos de seu registro, poderá requerer ao oficial de registro de imóveis a conversão desse título em registro de propriedade, tendo em vista sua aquisição por usucapião, nos termos do art. 183 da Constituição Federal.

Para que haja a conversão, determina a lei à apresentação de certidões do cartório distribuidor, demonstrando a inexistência de ações em andamento que caracterizem oposição à posse do imóvel objeto de legitimação de posse; declaração de que o possuidor não possui outro imóvel urbano ou rural; declaração de que o imóvel é utilizado para sua moradia ou de sua família; e declaração de que não teve reconhecido anteriormente o direito à usucapião de imóveis em áreas urbanas (Corrêa: 2012).

Faz-se notar, portanto, que há rigoroso ciclo de procedimentos e exigências para que o possuidor tenha reconhecido o direito de propriedade sobre seu imóvel.

Cabe ressaltar, entretanto, a necessidade de esperar cinco anos, depois de todos os percalços procedimentais para o registro da legitimação, para que seja reconhecida a propriedade pela usucapião.

Diante disso, algumas questões se impõem: Por que não declarar a propriedade pela legitimação administrativa apenas, tendo em vista que sua efetividade se observa após trâmite administrativo detalhado? Será que durante o lapso temporal em que ocorre a legitimação já consubstanciada, mas não convalidada em usucapião, poderá o possuidor perder sua posse? Nesse caso, há uma posse autorizada, mas não segura o suficiente para consolidar a propriedade, mesmo sendo obedecidas tantas exigências jurídicas? A modalidade aquisicional por usucapião poderá ser aplicada em bens públicos, uma vez que há proibição constitucional de fazê-lo? Seria, portanto, uma usucapião administrativa?

O presente trabalho sugere uma reavaliação do instituto da legitimação da posse como meio administrativo eficaz para promover a aquisição do direito de propriedade aos 
moradores de conglomerados habitacionais precários, com todas as faculdades inerentes ao proprietário (usar, gozar, dispor e reaver), sem tantos entraves burocráticos, sem que seja necessário a convolação para a usucapião, posto que tal exigência cria os óbices já descritos, impedindo, inclusive, a aplicação em bens públicos, inviabilizando uma política fundiária ampla, como seria o animus da Lei $\mathrm{n}^{\circ}$ 11.977/2009.

Percebe-se que, ainda que a lei exija lapso temporal para que haja a legitimação da posse e, dessa maneira, transforme a posse injusta em posse regular, consolidando tempo legal para que seja realizada a legalização da área ao transformar diretamente a legitimação em propriedade, inclusive em áreas de domínio público abandonadas, poder-se-á, uma vez reconhecido o domínio do terreno, adequar o direito de sobrelevação pela cisão nas unidades que ven am a estar constru das na superf cie, como ocorre no "direito de laje".

Determinado o princípio de que o primeiro ocupante assenta sua ocupação em propriedade, poderá ser feita a superfície em tantos graus quantos sejam necessários.

$\mathrm{Na}$ questão do lapso de tempo, sugere-se a aplicação do instituto da acessão de posse $^{13}$, haja vista que, há intensa mobilidade interna no interior de tais comunidades, principalmente na locação de quitinetes, o que no caso do Rio de Janeiro foi muito bem explicitado em trabalhos de campo realizados por Corrêa (2012) e Magalhães (2013).

Desta maneira, sendo absorvidos os tempos de posses anteriores na contagem do prazo que a norma estipula, poderá ser legitimada a melhor situação de posse em que se encontra o beneficiário, desde que consumado o tempo legal de posses, independentemente de quantos imóveis tenham sido habitados, pelo possuidor, no interior da mesma favela.

Caso contrário, se mantida a rigidez de contagem de prazo estipulado atualmente na lei, dois problemas podem apresentar-se: o primeiro é de ordem prática, uma vez que obriga que o morador não possa mudar para outro imóvel, o que não ocorre nas favelas, comumente.

Nesse quesito, a prática cartorial exercida pelas Associações de Moradores, conforme adverte Marcos Aurélio Bezerra de Melo (2015) poderia ser de grande utilidade, dada a existência da comprovação da cadeia de transmissão das posses arquivada em "registro". Seria estabelecer laços de cooperação entre o ente representativo da favela e o ente público, no sentido de aproveitar a organização já existente como forma de promover o acesso ao direito de propriedade, o que consistiria não só em um estágio mais avançado de regularização fundiária, bem como estreitar laços.

\footnotetext{
${ }^{13}$ Accessio temporis: Acréscimo de tempo ou prazo permitido por lei ou previsto em contrato, acessão de tempo, previsto no Art. 1.207, do Código Civil: "O sucessor universal continua de direito à posse do seu antecessor; e ao sucessor singular é facultado unir sua posse à do antecessor, para os efeitos legais”.
} 
Portanto, as reflexões aqui expostas indicam que as possíveis soluções para conceder acesso à moradia para pobres devem ser analisadas por uma ótica ampla, compreendendo a questão habitacional de maneira absolutamente integrante ao aspecto de cidadania, buscando instrumentos genuínos que capacitem novas formulações jurídicas e, consequentemente, sociais. Caso contrário, estarão sendo reproduzidos, de maneira reiterada, desamparos legais.

\section{Conclusão.}

Por fim, conclui-se que a questão da moradia no Brasil, em especial no Rio de Janeiro, advém de longa data, de modo que a questão habitacional se perfaz como um grave problema histórico, umbilicalmente relacionado com o a cidadania plena, razão pela qual tal direito encontra-se expressamente previsto dela Constituição Federal no rol dos Direitos Sociais.

Não obstante a clara vinculação do direito de moradia a concepção de dignidade humana, este ainda encontra grandes óbices a sua efetivação, principalmente no seio das grandes metrópoles, onde se perpetuam aglomerados habitacionais formados e mantidos através de arranjos sociais, carentes de reconhecimento e infraestrutura estatal.

Desta forma, reconhecemos que muito embora as favelas representem para grande parte da população uma solução para a questão habitacional, a falta de regularização e reconhecimento destas por parte do estado, faz com que seus habitantes experimentem uma cidadania muito restrita, vulnerável.

Essa condição de invisibilidade atribuída as favelas, institui uma grave segregação social que tem por base o acesso a moradia, à medida que observa-se um tratamento jurídico desigual, sendo certo que apenas aqueles inseridos no mercado formal é permitido desfrutar plenamente de sua cidadania e do direito de propriedade como se encontra previsto na codificação brasileira.

Dentro do universo dos arranjos praticados no âmbito informal das favelas, apresentamos neste paper o "Direito de Laje" e, após demonstrarmos sua inadequação aos instrumentos jurídicos existentes, sugerimos o que consideramos uma possibilidade real de conjugação de institutos para viabilizar a regularização das favelas, que conforme demonstramos, tem acentuado crescimento vertical, através da construção sobre "lajes".

Nesse sentido sugerimos uma aplicação dialógica de institutos, em resumo, após prévia regularização do solo por meio do procedimento de legitimação de posse, previsto na Lei 11.977/2009 -reestruturado para ser utilizado de forma mais ampla e menos burocrática- 
seria aplicado o Direito de Superfície, previsto no código civil, e seus dois desdobramentos, quais sejam: a cisão (com possibilidade de aplicação defendida pela melhor doutrina) e a sobrelevação (que embora não contemplada no ordenamento jurídico brasileiro, é um instituto utilizado em vários países europeus).

Concluímos que para tratar juridicamente questões sociais, é necessário a priori enxerga-las sob uma ótica de pluralismo, por meio da qual parte-se da premissa de que o direito é, sobretudo, um fenômeno de ordem social. Restando como principal função dos seus operadores, empregar uma interpretação hermenêutica com o objetivo de adaptar a objetividade da norma à complexidade e pluralidade social.

\section{Referências Bibliográficas.}

ASCENSÃO, José de Oliveira. Direito Civil: Reais. 5 ${ }^{\text {a }}$ Ed, Coimbra: Editora Coimbra, 2000.

CARBONARI, Sílvia Regina de Assumpção. O direito de superfície sob nova perspectiva. Disponivel em: http://www.ambito-juridico.com.br/site/index.php?n link=revista artigos leitura\&artigo id=2458

CARVALHO, José Murilo de. Cidadania no Brasil. O longo caminho. $2^{a}$ Ed. Rio de Janeiro: Civilização Brasileira, 2002.

Os bestializados. O Rio de Janeiro e a Republica que não foi. $3^{\mathrm{a}}$ Ed. São Paulo: Companhia das Letras, 2006.

CORRÊA, Cláudia Franco. Controvérsias entre o direito de moradia em favelas e o direito de propriedade imobiliária na cidade do Rio de Janeiro: "O direito de Laje" em questão. Rio de Janeiro: Topbooks, 2012.

FARIAS, Cristiano Chaves de; ROSENVALD, Nelson. Direitos Reais. $6^{\text {a }}$ Ed. Rio de Janeiro: Lumen Juris, 2009.

FILHO, José dos Santos Carvalho. Comentários ao estatuto da cidade. $2^{\mathrm{a}}$ Ed. Rio de Janeiro: Lumen Juris, 2006.

GONÇALVES, Rafael Soares. Les Favelas de Rio de Janeiro. Histoire et droit. XIX-XX Siècles. Paris: Editora Harmattan, 2010.

LESSA, Carlos. O Rio de todos os Brasis (Uma reflexão em busca de autoestima). Rio de Janeiro: Ed. Record, 2005.

LIRA, Ricardo Pereira. Elementos de direito urbanístico. Rio de Janeiro: Renovar, 1997.

$365,2002$. . O Direito de Superfície e o espaço aéreo. Revista forense, $\mathrm{n}^{\mathrm{o}} \mathrm{V}, \mathrm{p}$. 
MAGALHÃES, Alex Ferreira. Sociologia do Direito: O pluralismo jurídico em Boaventura de Sousa Santos. Rio de Janeiro: Editora UFRJ, 2013.

MELLO, Marco Aurélio Bezerra de. Curso de Direito Civil V-Direito das Coisas. Rio de Janeiro: Atlas, 2015.

RIBEIRO, Luiz Cesar de Queiroz. Dos cortiços aos condomínios fechados: as formas de produção da moradia na cidade do Rio de Janeiro. Rio de Janeiro, Civilização Brasileira/IPPUR-UFRJ/FASE,1997. 